\title{
Türkiye'de İç Göç Olgusunun Todaro Paradoksu Çerçevesinde Analizi: ARDL Sınır Testi Yaklaşımı
}

\section{Analysis of Internal Migration in Turkey Within The Framework of the Todaro Paradox: An ARDL Bound Testing Approach}

\author{
Emrah KIRATOĞLU1 ${ }^{10}$, İlknur Yeşim DiNÇEL ${ }^{2}$ (D)
}

\begin{abstract}
öz
İlkel toplumlarda bireysel ve kitlesel göçler mevcut alandan daha verimli ya da daha güvenli alanlara yerleşmek için gerçekleştirilmiştir. Modern dünyada ise özünde benzer sebepler olmakla beraber, yüksek refah seviyesine ulaşma, eğitim fırsatları ve istihdam olanaklarına erişme, savaş gibi sebeplerden ötürü göçler meydana gelmektedir. Gelişmekte olan ülkelerde kırdan kente yapılan göçlerin, kentlerdeki istihdam olanaklarındaki artışın sağladığı pozitif etkiyi yok edebileceği Todaro Paradoksu olarak iktisat teorisinde yer almaktadır. Bu çalışmada Türkiye'de 1988-2019 yılları arasında kentteki istihdam olanaklarının artışı ile kırdan kente yapılan göçlerin, kent işsizliğine etkisinin Todaro Paradoksu çerçevesinde ölçülmesi amaçlanmıştır. ARDL sınır testi sonucunda elde edilen bulgulara göre, Türkiye'de 1988-2019 yıllarında ilgili değişkenler arasında istatistiksel olarak anlamlı bir ilişki bulunmaktadır. Bir diğer deyişle, Türkiye'de kırdan kente yapılan göçler, kentteki istihdam imkanlarındaki artışı baskılamakta ve kentlerde işsizliği arttırmaktadır. Kırsal kalkınma politikaları ile beklenen gelirdeki artış desteklenmediği sürece, iç göçler üzerinde beklenen gelirin etkisi devam edecektir. Kent nüfusu içinde artan işsizlik ise giderek daha önemli iktisadi ve sosyolojik sorunlara neden olacaktır.
\end{abstract}

Anahtar kelimeler: İç göç, İşsizlik, Todaro paradoksu, ARDL sınır testi

JEL Sınıflaması: J61, R10, R23

\begin{abstract}
In primitive societies, individual and mass migration took place to settle in more productive and/or safer areas. In the modern world, migration occurs for similar reasons, such as obtaining a higher level of welfare, accessing educational and employment opportunities, and fleeing the dangers of war. The Todaro Paradox is an economic theory proposing that migration from rural to urban areas in developing countries can destroy the positive effect of increased urban employment opportunities. Based on the Todaro Paradox, this study sought to measure the effect of increased employment opportunities in cities and migration from
\end{abstract}

${ }^{1}$ Arş. Gör., Harran Üniversitesi, İktisadi ve İdari Bilimler Fakültesi, Maliye Bölümü, Şanlıurfa, Türkiye

${ }^{2}$ Arş. Gör., Harran Üniversitesi, İktisadi ve İdari Bilimler Fakültesi, İktisat Bölümü, Şanlıurfa, Türkiye

ORCID: E.K. 0000-0002-1571-081X; I.Y.D. 0000-0001-6367-7949

Sorumlu yazar/Corresponding author: illknur Yeșim DiNÇEL,

Harran Üniversitesi, İktisadi ve İdari Bilimler Fakültesi İktisat Bölümü, Harran Üniversitesi Osmanbey Kampüsü Haliliye Şanlıurfa Türkiye E-posta/E-mail: dincelyesim@gmail.com

Başvuru/Submitted: 01.10.2021

Revizyon Talebi/Revision Requested: 21.11.2021

Son Revizyon/Last Revision Received: 22.11.2021

Kabul/Accepted: 22.11.2021

Atıf/Citation: Kiratoğlu, E., Dincel, I.Y. (2021). Türkiye'de iç göç olgusunun Todaro paradoksu çerçevesinde analizi: ARDL sınır testi yaklaşımı. istanbul liktisat Dergisi - Istanbul Journal of Economics, 71(2), 527-548. https://doi.org/10.26650/ISTJECON2021-1003144 
rural to urban on urban unemployment in Turkey in the 1988-2019 time period. The findings obtained using ARDL bound testing reveal a statistically significant relationship between the relevant variables. Suggesting that migration from rural to urban areas in Turkey suppresses growth in employment opportunities and increases unemployment. As long as elevated expected income is not supported through rural development policies, internal migration will continue. Rising unemployment among urban populations will result in significant economic and sociological challenges.

Keywords: Internal migration, Unemployment, Todaro paradox, ARDL bound test

JEL Classification: J61, R10, R23

\section{EXTENDED ABSTRACT}

Migration is the act of individuals moving within or between countries due to force majeure or to achieve personal goals. Multiple socioeconomic factors can trigger decisions to migrate, and new communities and social lives are formed in both the area of migration and abandoned area as a result of such individual or mass movement.

The phenomenon of migration, which is high on the agenda of many countries across the globe, has a very important place due to changing living standards. The living conditions of abandoned regions of international or national human flows have been observed as more negative to human flourishing than the preferred region. At the same time, issues such as unplanned urbanization, increased crime rates, interpersonal communication challenges, and racism can arise in the migration from underdeveloped regions to developed regions.

Concerning the attempt to maintain a balance in class relations between individuals in the same region, migration from irregular and underdeveloped regions results in income differences, particulary related to employment which are at the forefront of rising crime and incompatibility in a society defined by the rule of law.

Hope of a better life, health, or employment opportunities is called internal migration. The first data on internal migration in Turkey was obtained by Turkstat in the 1970 general population census by asking the place of residence of the people in the previous year. The causes of internal migration in Turkey have over time. While immigration occurred for reasons such as job changes and marriage in the early years of the Republic, in the advent of technological development and industrialization, mobility from rural to urban areas and from city to city occured 
in the subsequent periods. In addition to various appealing factors, such as city's zoning amnesty, terrorist incidents in the east of the country increased migration movements from east to west.

As the Turkish economy evolved from agriculture to industry and service sectors, internal migration became prominent and attracted attention starting in the 1950s. In this context, migration from rural areas to city centers accelerated urbanization. As a result of internal migration movements in Turkey over the years, significant differences in interregional development and interregional population densities have emerged. Since the service standards offered by the cities are more attractive to individuals, there are now regional variations in health, environment, employment, social, and economic factors. Intense transitions occurred in the eastern parts of the country, especially to the Marmara Region. Among the main reasons for this circumstance are the rising mechanization of agriculture, increasing unemployment in villages, education opportunities in cities, and security.

In this study, from perspective of the Todaro Paradox, the significant weakening of new employment opportunities in cities due to internal migration was tested using the ARDL limit test, examing internal migration and urban unemployment rates the years from 1988 to 2019 and the validity of the Todaro Paradox for Turkey. The findings revealed a significant relationship between the urban employment rate, rural population rate, and urban unemployment rate for 19882019 in Turkey. The analysis demonstrates that the positive effect of increasing employment opportunities in Turkish cities in reducing the unemployment rate is diminished by internal migration. This result confirms the validity of the Todaro Paradox in Turkey between 1988 and 2019. In other words, continuous increase in employment opportunities in cities triggers rural migration to cities causing unemployment to become endemic.

These findings are congruent with other studies examining the relationship between immigration to cities and unemployment in cities. It would not be incorrect to assert that urban immigration is related to multiple issues, such as population density, unplanned urbanization, insufficient infrastructure, and traffic 
complications. It is insufficient to develop policy packages based only on cities to address such changelles. Policies aimed at managing the problems experienced in cities should include regional aspect aimed at increasing employment opportunities and improving living standards in rural areas. When individuals do not face unemployment in the region in which they live and if they feel that education, health, and security are sufficient, they will tend to be more cautious and hesitant regarding migration. At this point, encouraging reverse migration with rural development policies is an important consideration for preventing internal rural-urban migration, which is triggered by low incomes and lack of living standards in rural areas compared to urban areas. 


\section{Giriş}

Göç, bireylerin mücbir sebeplerden veya kendi hedeflerini gerçekleştirebilmek için ülkelerarası ya da ülke içinde yaptıkları yer değişikliği eylemidir. Nitekim göç etme kararını tetikleyen birçok sosyoekonomik faktörün yanı sıra, bireylerin ya da geniş kitlelerin hareketi sonucunda göç edilen ve terk edilen alanda yeni bir toplumsal hayat oluşmaktadır.

Göç hareketlerinin planlı olması ile aynı bölgedeki bireyler arasındaki sınıfsal ilişkilerde denge sağlanırken; düzensiz ve az gelişmiş bölgeden yapılan göçler başta istihdam olmak üzere gelir farklılıklarının artması, suç olgusunun ön plana çıkması ve toplumda sosyal uyumsuzluk gibi durumlar da yaşanmaktadır.

Aynı ülke içinde daha iyi yaşam, sağlık veya istihdam olanakları için yapılan değişim hareketine iç göç denilmektedir. Türkiye'de iç göçlere ilişkin ilk veri Türkiye İstatistik Kurumu (TÜIK) tarafından 1970 yılı genel nüfus sayımlarında, kişilerin bir önceki sayımda ikamet ettiği yeri sorularak elde edilmiştir (Ercilasun, M., Gencer, E ve Esin, 2011, 320). Türkiye'de iç göçlerin nedenleri dönem dönem değişme göstermiş̧ir. Cumhuriyetin ilk yıllarında görev yeri değişiklikleri, evlilik gibi sebeplerle göç edilirken, sonraki dönemlerde teknolojik gelişmeler ile sanayileşme ile kırdan kente ve kentten kente hareketlilikler yaşanmıştır. Büyükşehirlerde imar affı gibi cezbedici faktörlerin yanı sıra ülkenin doğusunda meydana gelen terör olayları doğudan batıya doğru göç hareketlerini arttırmıştır.

Bu çalışmada Todaro Paradoksu çerçevesinde, kentlerde yaratılan yeni istihdam olanaklarının iç göçler sebebiyle önemli ölçüde zayıflama gösterme durumu ARDL sınır testi ile sınanmıştır. Bu çerçevede 1988-2019 yılları arasında iç göç ve kentsel işsizlik oranları ile Todaro Paradoksu'nun Türkiye için geçerli olma durumu incelenmiştir. Elde edilen bulgular ile iç göçlerin kent istihdamı üzerindeki olumsuz etkisinin varlığı ve boyutu somut olarak ortaya konulması amaçlanmaktadır. 


\section{Kavramsal ve Kuramsal Olarak Göç}

Toplumsal bir eylem olarak göç Uluslararası Göç Örgütü tarafından, bir kişinin veya bir grup insanın uluslararası bir sınırı geçerek ya da bir ülke içinde yer değiştirmesi olarak tanımlanmıştır (Uluslararası Göç Örgütü, s.35). Bu tanım mültecileri, yerinden edilen bireyleri, istihdam edilmek üzere yer değiştirenleri, evlilik gibi sebeplerle göç edenleri kapsamaktadır. Tanımdan anlaşılacağı üzere göç yalnızca ulus aşırı değil, ülke sınırları içinde de gerçekleşmektedir.

Tekeli göç etme nedenleri dört başlık altında gruplandırmıştır (Tekeli,1975, 158). Illk olarak göç, sosyal sistemdeki dengesizliklerin giderilmesi için ortaya çıkan bir mekanizmadır (Wolpert, 1966). Dengesizlikler veri alınarak ne kadar göçe neden olduğu incelenerek net göç ile sistemin dengeye ulaşacağı varsayılmaktadır (Okun ve Richardson, 1961). İkinci olarak göç, toplumların dönüşüm süreçlerinde görülen tek taraflı bir harekettir. Bu tür göçleri işgücü talebi ve arzı arasındaki uyumsuzluklar ile ücret düzeylerindeki farklılıklar üzerinden açıklamak mümkündür (Kuznets, 1963). Bir diğer göç analizi ise net göç olgusu yerine toplumdaki hareketliliği bütünüyle ele almaktadır. Toplumda bir dönüşüm süreci olmasa dahi mutlaka bir göç süreci yaşanacaktır (Tolley, 1963, 11). Bu noktada göç kişilerin heterojenliğinden, toplumdaki rollerini seçme süreçlerinden kaynaklanmaktadır. Son olarak göç, politik süreçler sonucunda uygulanan göç politikalarını kapsamaktadır (Friedman, 1966). Geri kalmış bölgelerden gelişmiş bölgelere olan işgücü kaymasını azaltacak teşvik sistemleri bu grup göç analizine örnektir.

Göç, bırakılan ve yerleşilen bölgede toplumsal sınıf ilişkilerini değiştirebilecek sonuçlara neden olmaktadır (Hutchinson, 2009, 47). Ayrıca yalnızca mekanlar değil, göç eden kişide de çeşitli değişimler gözlemlenmektedir (Griworld, 2009, 43-45). Dengesiz nüfus hareketliliği, kentlere yapılan göç ile kentlerde suç oranlarının artışı, kültürel çatışma, toplulukların uyum sürecinde zorluklar yaşaması göçün dikkat çeken olumsuz taraflarındandır. İstihdam ve üretime katılan kitlenin artışı ile işsizliğin doğurduğu sıkıntıların giderilmiş olması göç olgusunun olumlu yanı olarak sayılabilmektedir (Akkayan, 1979, 22). 
Göç olgusuna farklı bir perspektiften bakılacak olursa, cinsiyet ayrımcılığı dikkat çekmektedir. Göçün başlangıç döneminde erkek göçmen sayısının kadın göçmene göre fazla oluşu, ancak göç edilen yerde kurulu düzen sağlandıktan sonra kadın göçmen nüfusunun ivme kazanması göç olgusunda cinsiyetin ön plana çıkan taraflarındandır (Tekeli, 1998, s.11-15).

Göç üzerine yapılan tanımlardan da anlaşıldığı üzere ülke sınırlarına göre iç ya da dış, isteğe göre gönüllü ya da zorunlu göç olarak kategorize edilebilmektedir. Dış göç; ülke sınırları dışına yapılan uzun ya da kalıcı yer değiştirme, iç göç; ülke sınırları içinde bir yerel yönetimden diğer yerel yönetime geçiş (Toksöz, 2006, 23), gönüllü göç; göç edilecek yerin mevcut yaşanılan yere daha cazip oluşu nedeniyle iradi olarak yapılan yer değişikliği (Tümtaş ve Ergun, 2014,4) ve zorunlu göç ise nüfusun yaşadığı bölgeden zorla çıkarılması (Barut, 2011, 20) olarak tanımlanabilmektedir.

Ülke sınırları içinde bir yerel yönetimden diğerine yapılan iç göçleri açıllamaya yönelik çeşitli teoriler ve görüşler bulunmaktadır. Ravenstein'e göre göç edenlerin çoğunluğu kısa mesafedeki yerlere göç etmektedir (Ravenstein, 1985). Ayrıca kadınlar daha kısa mesafelere göç ederken, erkekler uzun mesafeli yerlere göç etmektedir. Bunun yanı sıra göç edenler, gittikleri mekanın iktisadi ve sosyal refahını paylaşmak istemektedir.

Stouffer'a göre, göç ile mesafe arasında doğrudan bir ilişki bulunmamakla beraber göç edilen yerdeki istihdam olanakları göçe teşvik eden unsurların başında gelmektedir (Stouffer, 1940). Lee ise göçü etkileyen faktörler olarak yaşanan yer, göç edilecek yer, kişisel unsurları sıralamaktadır (Lee, 1966). Sjaatad'a göre, göç etme kararı verilirken göç maliyetlerini ve göç getirilerini karşılaştırılarak düşük kazanç bölgelerinden yüksek kazanç bölgelerine yönelim gerçekleşmektedir (Sjaastad, 1962). Lewis'in ikili ekonomi teorisine göre, kırsal tarım ve kentsel sanayi olmak üzere iki sektör bulunmaktadır. Lewis'in çalışmasında kırdan kente göç ile iktisadi gelişme ilişkisini sayısal veriler üzerinden analiz etmiştir (Lewis, 1954).

Todaro ise kentteki istihdam artışının göç ve kentsel işsizlik üzerindeki etkisini incelemiştir. Buna göre ücret farklılıklarının kırsal-kentsel göçte davranış modelini 
formülize etmiştir. Analizde eksik istihdam varsayımı geçerlidir (Todaro, 1969, 138). Kentsel emek arzının belirleyicileri analiz edilirken reel gelir farklılılarından ziyade beklenen gelir farklılığına bakılmalıdır. Beklenen gelir farklılıkları kentsel işsizlik oranı üzerinde dengeleyici bir güç olarak kabul edilmektedir.

Todaro, az gelişmiş ülkelerde işçi göçünü baz alarak, göçü iki aşamalı bir olgu olarak kabul etmektedir. İlk aşamada vasıfsız kırsal iş̧̧inin bir kentsel alana göç etmekte ve belirli bir süreyi informal sektörde geçirmektedir. İkinci aşama ise modern sektörde istihdam edilmesiyle gerçekleşmektedir. Bu iki aşamalı süreç; göç kararına, informal sektörün orantılı büyüklüğüne, endüstriyel büyümeye ve kırsal-kentsel reel gelir farklılıklarının modern ekonomide işgücüne katılım üzerindeki etkilerine ilişkin sorulara cevap içermektedir.

Harris ve Todaro ise şehirdeki asgari ücretin oldukça yüksek olduğu, işsizliğin olmadığı, iki sektörlü, sektörler arasında gelir ve üretim ayrımının yapıldığı bir göç modeli kurgulamışır (Harris ve Todaro, 1970, 126). Modelde dengeleyici unsur olan kentsel istihdam oranı ile kent-kır gelir farklılıkları arasındaki ilişki incelenmiştir. Harris ve Todaro'nun modeline göre beklenen kentsel gelir kırsal gelire eşitlenene dek göç devam edecektir. Öte yandan, tarımsal gelirdeki bir artış, sanayi üretiminde herhangi bir azalma olmaksızın tersine göçü tetikleyecektir. Dolayısıyla, tarım sektöründe emeğin fırsat maliyeti sanayi sektörüne göre daha düşük düzeydedir (Harris ve Todaro, 1970, 132).

Todaro modeli pek çok araştırmacı tarafından çeşitli şekillerde sınanmıştır. Nakagome kurduğu mekânsal işgücü piyasasında, kentte beklenen gelir seviyesinin yüksek olması sonucu, göç hareketlerinin hız kazanacağına, bir diğer ifade ile Todaro Paradoksunun geçerli olacağı sonucuna ulaşmıştır (Nakagome, 1989). Takagi ise Todaro Paradoksunun hangi koşullarda geçerli olacağını araştırmıştır (Takagi, 1984). Görüldüğü üzere Todaro ve onu takip eden düşünürlerin kentselkırsal gelir üzerinden yaptıkları göç değerlendirmeleri, göçün sosyoekonomik sonuçları adına etkili bir bakış açısı oluşturmaktadır. Zira Todaro'nun çalışmaları sonrasında göç alan ve göç veren bölgelerin sosyal yapılarında meydana gelen değişimlerin yanı sıra iktisadi bozulmalar da ön plana çıkmıştır. 


\section{Türkiye'de İç Göçler}

2005 yılında ismi TÜiK olarak değiştirilen Devlet İstatistik Enstitüsü, ilk kez 1970 yılı genel nüfus sayımlarında kişilerin bir önceki sayımda ikamet ettiği yeri sormuş ve sonraki genel nüfus sayımlarında bu soruyu sormaya devam etmiştir (Ercilasun vd., 2011, 320). Böylece Türkiye'de iç göçlere ilişkin veri elde edilmeye başlanmıştır.

Türkiye'de iç göçler tarihsel düzlemde dört dönem üzerinden incelenebilmektedir (Şahin, 2018, 39): 1923-1950 dönemi, 1950-1960 dönemi, 1960-1980 dönemi ve 1980 ve sonrası dönem.

1923-1950 döneminde göç hareketleri genel itibariyle tayin, evlilik ve eğitim sebepleriyle gerçekleşmiştir (Özdemir, 2012, 2). 1950-1960 dönemi Marshall Planı'nın etkisiyle tarımda teknolojik gelişmelerin görüldüğü dönem olmuştur. Tarım sektöründe verimlilikte artış yaşanırken, işsizlik de baş göstermiş ve kırdan kente hızlı bir şekilde göçler başlamıştır (Kurt, 2003, 69). Bu durum şehirlerde gecekondulaşmayı beraberinde getirmiştir.

1960-1980 döneminde, kırdan kente göç eden, gecekonduda yaşayan ve kayıt dışı sektörlerde bulunan kitle, kent nüfusunun büyük bir parçası haline gelmiştir. 1955 yılında kentlerde gecekonduda yaşayan nüfus, kent nüfusunun \%5,7'si iken, 1980 yılına gelindiğinde \%26,1 oranına ulaşmıştır (Şen, 2014, 248). 1960-1970'li yıllarda kırdan kent göç ağırlıktayken, 1970'lerin sonunda kentten kente göçler dikkat çekmeye başlamıştır (İçduygu ve Sirkeci, 1999, 252).

1980 ve sonrası ise Türkiye'de piyasa ekonomisinin oluşmaya başladığı dönemdir. Bu dönemde çıkarılan imar affı büyükşehirlere göç için yeni bir neden doğurmuştur (Şahin, 2018, 43), Ayrıca ülkenin doğusunda yaşanan terör olayları da bölge insanını göçe zorlayan unsurlar arasındadır. 1985 yılında ilk defa kent nüfusu kır nüfusunu aşmışır. 2012 yılında 6360 sayılı kanun ile 14 il büyükşehir 
statüsü kazanmış ve ayrıca 27 ilçe kurulmuştur ${ }^{1}$. Bu kanun ile kırsal nüfusun bir kısmı kentsel nüfusa aktarılmıştır. Kanun ile köy statüsünden mahalle statüsüne kavuşan, diğer bir ifade ile, ilçe belediyelerinin kapsamında olan köylerin büyükşehir belediyeleri kapsamına girmesiyle; bu yerlerin daha fazla hizmet alması ve kırdan kente göçlerin yavaşlaması hatta tersine göçün başlaması beklenmekteydi. Ancak yerel yönetimlerdeki bu değişim beklenen etkiyi yapmamış, suni bir değişim olarak kalmıştır. Bu durum çalışmada kullanılan değişkenlerin zaman serisi grafiklerinden de takip edilebilmektedir. Şekil 1'de toplam nüfus içinde kırsal nüfusun oranı sunulmuştur. Görüldüğü üzere, kırsal nüfus sürekli olarak kentlere doğru kaymıştır.

Şekil 1. Toplam Nüfus İçinde Kırsal Nüfusun Oranı

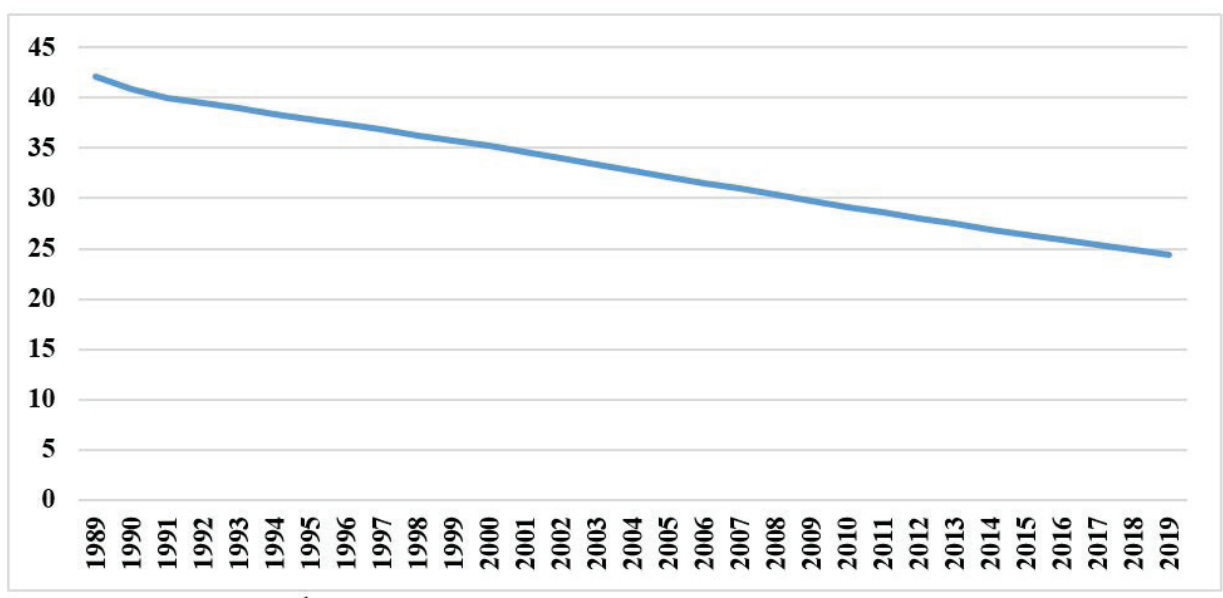

Kaynak: Dünya Bankası

Türkiye'de iç göçler üzerine yapılmış çeşitli çalışmalar bulunmaktadır. Yener (1977), 1965-1970 yıllarındaki göçleri ve göçmenlerin sosyoekonomik özelliklerini incelemiştir. Kocaman ve Bayazıt (1993) 1965-1985 dönemindeki iç göçleri ele alırken, Eraydın (1981) ise 1950-1980 iç göçlerini ele almıştır. Gedik (1994), 19651970, 1975-1980, 1980-1985 ve 1985-1990 dönemlerindeki göç hareketlerini incelemiştir. Tümertekin (1977), göç veren alanlardaki değişim ve sonuçlarına

\footnotetext{
128489 Sayılı Resmi Gazete, 6360 Sayılı On Dört İlde Büyükşehir Belediyesi ve Yirmi Yedi İlçe Kurulması ile Bazı Kanun ve Kanun Hükmünde Kararnamelerde Değişiklik Yapılmasına Dair Kanun.
} 
odaklanırken, başka bir çalışmasında (Tümertekin, 1971) Raveenstein'in bireylerin kademeli göçü hipotezini İstanbul üzerinden test etmiştir. Gür ve Ural (2004), Türkiye'de 1990 yılı iç göçlerini itici-çekici faktörler üzerinden açıklamıştır. Cerit (1986), 1950-1980 döneminde bireylerin doğdukları illeri temel alarak ömür boyu göçü ortaya koymuştur. Yamak ve Yamak (1999), 1980-1990 dönemindeki göç-gelir ilişkisini analiz etmiştir ve şehirlerarası gelir farklılıklarının göç üzerinde önemli etkisi olduğu sonucuna ulaşmıştır. Mutlu (1990), 1973-1986 arasındaki bölgesel iç ticaret hadlerinin kırsal refah ve iç göç üzerindeki etkisi üzerinde durmuştur. Çelik (2007), Türkiye'deki 1980-2000 arası iç göçlerin yönünü incelemiştir. Kıratoğlu (2019), Şanlıurfa ve Diyarbakır'daki göç hareketlerinin bölgesel kalkınma üzerindeki olumlu ve olumsuz bileşenlerini araştırmıştır.

Şekil 2'de Türkiye'nin göç etkinlik oranı harita üzerinde sunulmuştur. Koyu renkli gösterilen şehirler göç verirken, açık renkteki şehirler göç almaktadır. Buna göre Doğu Anadolu ve Güneydoğu Anadolu Bölgesi'ndeki pek çok şehir göç vermekteyken, özellikle Marmara Bölgesi şehirleri göç almaktadır. Hizmet çeşitliliği, türü, ölçeği, alanı ve kapsamındaki artışa paralel artan ihtiyaç ve gereksinimlerin karşılanması neticesinde oluşan kentlerdeki istihdam imkânlarının artmasında göçlerin payının çok büyük olduğunu söylemek yanlış olmayacaktır. Kırsal kesimdeki gelirin kente oranla düşük kalmasının tetiklediği göçün önüne geçilebilmesi için kırsal kalkınma politikaları ile tersine göçün teşvik edilmesi bu noktada önem kazanmaktadır. 


\section{Şekil 2. Türkiye'de İç Göç Etkinliği (2017)}

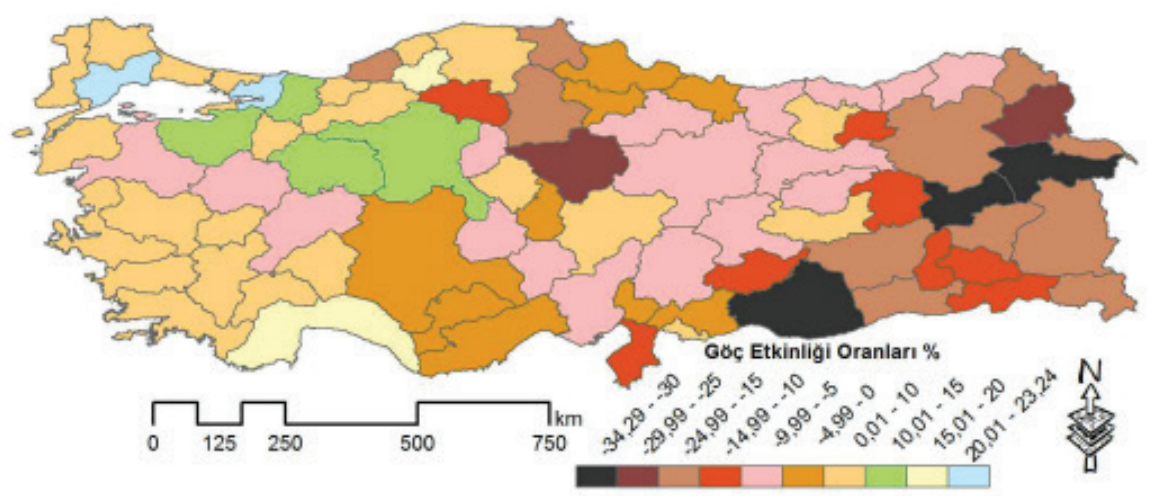

Kaynak: Birinci (2017), s.85.

\section{Metodoloji ve Veri Seti}

Bu çalışmada Türkiye'de 1988-2019 dönemleri arasında kentteki istihdam olanaklarının artışı ile kırdan kente yapılan göçlerin, kent işsizliğine etkisinin ölçülmesi amaçlanmıştır.

Çalışmada bağımlı değişken kentsel işsizlik oranıdır. Kentsel işsizlik ve kentsel istihdam oranı verileri Türkiye İstatistik Kurumu verilerinden elde edilmiştir. Kırsal nüfusun toplam nüfusa oranı ise Dünya Bankası verilerinden elde edilmiştir. Çalışmadaki analizler E-Views 11 programı aracılığıyla yapılmıştır. Tablo 1'de değişkenlere ilişkin bilgiler sunulmuştur.

Tablo 1: Modelde Yer alan Değişkenler

\begin{tabular}{|l|l|c|c|c|c|}
\hline Değişken & Açıklama & Birim & Kaynak & Dönemler & Gözlem Sayısı \\
\hline Kissiz & Kentsel İşsizlik Oranı & $\%$ & TÜiK & $1988-2019$ & 32 \\
\hline Kisth & Kentsel İstihdam Oranı & $\%$ & TÜiK & $1988-2019$ & 32 \\
\hline knufus & $\begin{array}{l}\text { Kırsal Nüfusun Toplam } \\
\text { Nüfusa Oranı }\end{array}$ & $\%$ & Dünya Bankası & $1988-2019$ & 32 \\
\hline
\end{tabular}

Ancak Johansen (1988), Engle-Granger (1987) ve Johansen-Juselius (1990) testleri, değişkenler birinci farkta durağan oldukları durumda uygulanabilmektedir. 
Pesaran, Shin ve Smith (2001) vd. geliştirdiği ARDL sınır testi gibi çeşitli eşbütünleşme testleri kullanılarak sınandığı görülmektedir. Ancak Johansen, EngleGranger ve Juselius testleri, değişkenler birinci farkta durağan oldukları durumda uygulanabilmektedir. Pesaran vd. geliştirmiş oldukları ARDL sınır testi ise bu durumu zorunluluk olmaktan çıkarmıştır. ARDL testi ile farklı düzeylerde durağan olan serilerde de eşbütünleşme testi yapmak mümkündür. Bunun yanı sıra ARDL testi küçük örneklemlerde diğer eşbütünleşme testlerine göre daha iyi çalışmaktadır (Narayan ve Narayan, 2004). ARDL sınır testinde değişkenler farklı seviyelerde durağan olabilirken, I(2) ya da daha yüksek seviyelerde durağan olmamalıdır.

ARDL sınır testi yaklaşımı için kısıtsız hata düzeltme modeline dayalı eşitlik aşağıdadır:

$\Delta \mathrm{kissiz}=\beta_{0}+\sum_{\mathrm{i}=1}^{\mathrm{m}} \beta_{1 \mathrm{i}} \Delta$ kissiz $_{\mathrm{t}-\mathrm{i}}+\sum_{\mathrm{i}=0}^{\mathrm{m}} \beta_{2 \mathrm{i}} \Delta$ kisth $_{\mathrm{t}-\mathrm{i}}+\sum_{\mathrm{i}=0}^{\mathrm{m}} \beta_{3 \mathrm{i}} \Delta$ knufus $_{\mathrm{t}-\mathrm{i}}+\beta_{4 \mathrm{i}} \mathrm{kissiz}_{\mathrm{t}-1}+\beta_{5 \mathrm{i}}$ kisth $_{\mathrm{t}-1}+$

$$
\beta_{6 \mathrm{i}} \mathrm{knufus}_{\mathrm{t}-1}+\varepsilon
$$

Burada $\Delta$ işareti birinci farkları, $\mathrm{m}$ ise gecikme sayısını temsil etmektedir. Hesaplanan F istatistiği Pesaran vd. (2001) çalışmalarındaki kritik değerlerle karşılaş̧ırılarak serilerin eşbütünleşik olup olmadığına karar verilir. Daha sonra kısa ve uzun dönem ilişkileri tespit etmek için ARDL modeli kurulur.

Seriler arasındaki ilişkiyi incelemek için kurulan ARDL modeli aşağıda verilmiştir. Denklemdeki m, n, p ise gecikme sayılarını göstermektedir.

$\Delta \mathrm{kissiz}=\beta_{0}+\sum_{\mathrm{i}=1}^{\mathrm{m}} \beta_{1 \mathrm{i}} \Delta \mathrm{kissiz}_{\mathrm{t}-\mathrm{i}}+\sum_{\mathrm{i}=0}^{\mathrm{n}} \beta_{2 \mathrm{i}} \Delta \mathrm{kisth}_{\mathrm{t}-\mathrm{i}}+\sum_{\mathrm{i}=0}^{\mathrm{p}} \beta_{3 \mathrm{i}} \Delta$ knufus $_{\mathrm{t}-\mathrm{i}}+\varepsilon$

\section{Ampirik Bulgular}

Çalışmada yapılan analiz 1988-2019 yıllarını kapsamaktadır. 1988 yılı öncesi verilere serilerin tümünde ulaşılamadığı için, 1988 sonrası dönem ile sınırlı tutulmuştur. Değişkenlere ilişkin tanımlayıcı istatistikler, korelasyon matrisi ve zaman serisi grafikleri aşağıda sırasıyla verilmiştir. 
Tablo 2: Değişkenlere İlişkin İstatistikler

\begin{tabular}{|l|c|c|c|c|}
\hline & Ortalama & Maksimum & Minimum & Standart Sapma \\
\hline kissiz & 12.42813 & 16.60000 & 8.80000 & 1.604275 \\
\hline kisth & 41.21563 & 47.40000 & 37.1000 & 2.877960 \\
\hline knufus & 33.10009 & 43.41300 & 24.3700 & 5.498740 \\
\hline
\end{tabular}

Tablo 3: Korelasyon Matrisi

\begin{tabular}{|l|c|c|c|}
\hline & kissiz & kisth & knufus \\
\hline Kissiz & 1 & 0.02763911 & -0.2909147 \\
\hline Kisth & 0.02763911 & 1 & -0.5367288 \\
\hline Knufus & -0.2909147 & -0.53672888 & 1 \\
\hline
\end{tabular}

Şekil 3. Değişkenlere Ait Zaman Serisi Grafikleri
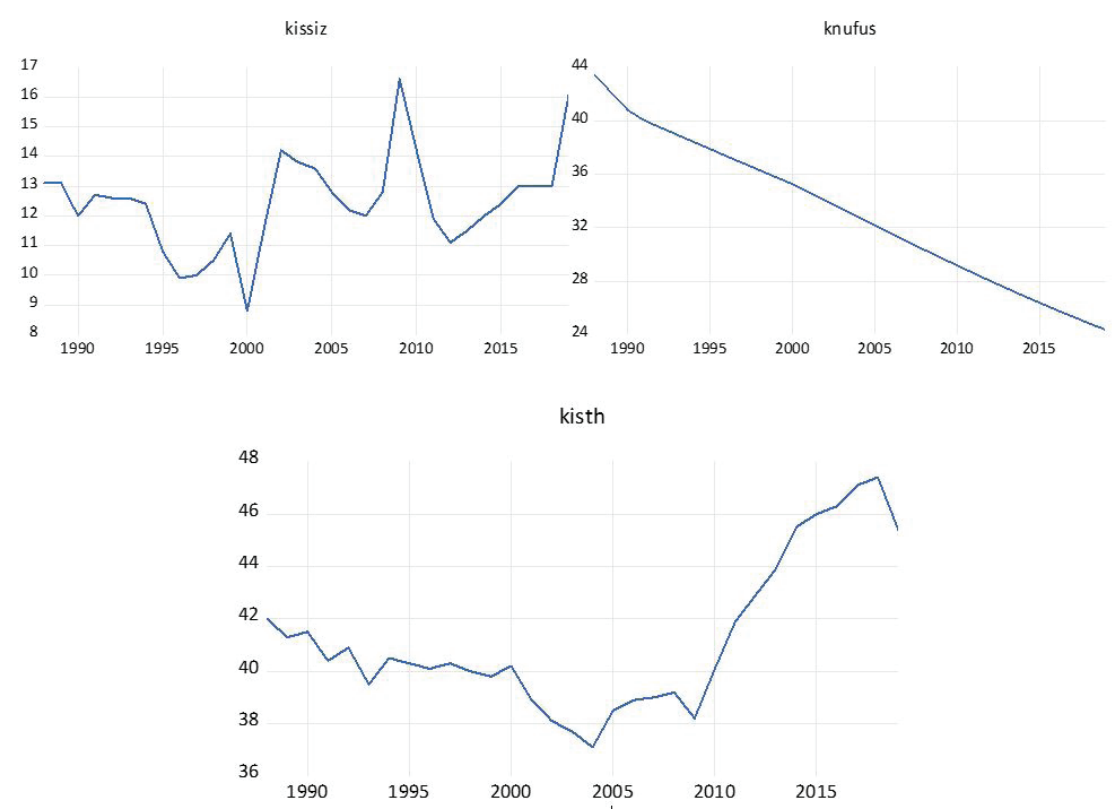

Zaman serisi analizlerinde istatistiksel olarak güvenilir sonuçlar elde etmek için, değişkenlerin durağan olması gerekmektedir. Değişkenler arasındaki ilişkiler araştırılmadan önce birim kök testleri yapılmıştır. ADF birim kök testi sonuçları Tablo 4'te verilmiştir. Buna göre kentsel işsizlik ve kentsel istihdam serileri 1. farkları alındıktan sonra durağanlaşırken, kırsal nüfusun toplam nüfusa oranını gösteren seri düzeyde durağandır. 
Tablo 4: ADF Birim Kök Testi Sonuçları

\begin{tabular}{|c|c|c|c|c|c|}
\hline Değişken & Kritik Değer & Sabitli & Olasılık & Sabitli ve Trendli & Olasılık \\
\hline \multirow[t]{2}{*}{ kissiz } & $\begin{array}{l}\% 1 \\
\% 5 \\
\% 10\end{array}$ & $\begin{array}{l}-3.661661 \\
-2.960411 \\
-2.619160\end{array}$ & \multirow[t]{2}{*}{0.1683} & $\begin{array}{l}-4.284580 \\
-3.562882 \\
-3.215267\end{array}$ & \multirow[t]{2}{*}{0.2616} \\
\hline & Test İst. & -2.333699 & & -2.652540 & \\
\hline \multirow[t]{2}{*}{$\Delta$ kissiz } & $\begin{array}{l}\% 1 \\
\% 5 \\
\% 10\end{array}$ & $\begin{array}{l}-3.670170 \\
-2.963972 \\
-2.621007\end{array}$ & \multirow[t]{2}{*}{0.0005} & $\begin{array}{l}-4.296729 \\
-3.568379 \\
-3.218382\end{array}$ & \multirow[t]{2}{*}{0.0022} \\
\hline & Test İst & -4.882080 & & -4.921018 & \\
\hline \multirow[t]{2}{*}{ kisth } & $\begin{array}{l}\% 1 \\
\% 5 \\
\% 10 \\
\end{array}$ & $\begin{array}{l}-3.670170 \\
-2.963972 \\
-2.621007 \\
\end{array}$ & \multirow[t]{2}{*}{0.8433} & $\begin{array}{l}-4.284580 \\
-3.562882 \\
-3.215267\end{array}$ & \multirow[t]{2}{*}{0.8190} \\
\hline & Test İst & 0.654510 & & -1.468127 & \\
\hline \multirow[t]{2}{*}{$\Delta$ kisth } & $\begin{array}{l}\% 1 \\
\% 5 \\
\% 10 \\
\end{array}$ & $\begin{array}{l}-3.670170 \\
-2.963972 \\
-2.621007 \\
\end{array}$ & \multirow[t]{2}{*}{0.0026} & $\begin{array}{l}-4.296729 \\
-3.568379 \\
-3.218382 \\
\end{array}$ & \multirow[t]{2}{*}{0.0093} \\
\hline & Test İst & -4.206137 & & -4.326935 & \\
\hline \multirow[t]{2}{*}{ knufus } & $\begin{array}{l}\% 1 \\
\% 5 \\
\% 10 \\
\end{array}$ & $\begin{array}{l}-3.679322 \\
-2.967767 \\
-2.622989\end{array}$ & \multirow[t]{2}{*}{0.8111} & $\begin{array}{l}-4.296729 \\
-3.568379 \\
-3.218382 \\
\end{array}$ & \multirow[t]{2}{*}{0.0011} \\
\hline & Test İst & -0.775460 & & -5.217703 & \\
\hline \multirow[t]{2}{*}{$\Delta$ knufus } & $\begin{array}{l}\% 1 \\
\% 5 \\
\% 10 \\
\end{array}$ & $\begin{array}{l}-3.679322 \\
-2.967767 \\
-2.622989 \\
\end{array}$ & \multirow[t]{2}{*}{0.0001} & $\begin{array}{l}-4.309824 \\
-3.574244 \\
-3.221728 \\
\end{array}$ & \multirow[t]{2}{*}{0.0000} \\
\hline & Test İst & -16.52388 & & -15.72214 & \\
\hline
\end{tabular}

*Değişkenlerin başında bulunan $\Delta$ birinci farkı ifade etmektedir.

Değişkenlerin farklı düzeylerde durağan olması eşbütünleşme testi olarak ARDL sınır testinin kullanılmasını gerektirmektedir. Tablo 5 'te ARDL sınır testi sonuçları verilmiştir. Değişkenlere ait uygun gecikme uzunlukları E-views 11 paket programından elde edilen Akaike bilgi kriterleri dikkate alınarak belirlenmiş ve $\operatorname{ARDL}(1,2,4)$ modelinde karar kılınmıştır. $F$ istatistik değerinin tüm önem düzeylerinde üst sınırdan büyük oluşu, değişkenler arasında eşbütünleşme ilişkisi olduğunu kanıtlamaktadır. 
Tablo 5: Sınır Testi Sonuçları

\begin{tabular}{|l|c|c|c|c|c|}
\hline Model & K & F İstatistiği & Önem Düzeyi & Alt Sınır & Üst Sınır \\
\hline \multirow{2}{*}{ ARDL(1,2,4) } & \multirow{2}{*}{2} & \multirow{2}{*}{10.04483} & $\% 10$ & 3.393 & 4.41 \\
& & & $\% 5$ & 4.183 & 5.333 \\
& & $\% 1$ & 6.14 & 7.607 \\
\hline
\end{tabular}

*k bağımsız değişken sayısını göstermektedir. Kritik değerler, Pesaran vd.(2001)'den alınmış olup \%5 anlamlıık düzeyindeki değerlerdir.

Hesaplanan F istatistiği kritik değerden büyük olduğu için Türkiye'de kentsel işsizlik oranı, kent istihdam oranı ve toplam nüfus içinde kırsal nüfus oranının 19882019 yılları için uzun dönemli eşbütünleşik olduğu sonucuna ulaşılmaktadır. Bu adımdan sonra uzun ve kısa dönem katsayıları hesaplanmaktadır. Maksimum 4 gecikme ve Akaike Bilgi Kriteri kullanılarak elde edilen ARDL $(1,2,4)$ modeli için uzun ve kısa dönem katsayıları Tablo 6'da sunulmuştur.

Tablo 6: ARDL Uzun ve Kısa Dönem Katsayı Tahminleri

\begin{tabular}{|l|l|l|l|l|}
\hline Değişken & Katsayı & Standart Sapma & t-istatistiği & Olasılık \\
\hline$\Delta$ (kisth) & -0.999363 & 0.189683 & -5.268595 & 0.0001 \\
\hline$\Delta$ (kisth(-1)) & -0.671095 & 0.221894 & -3.024399 & 0.0073 \\
\hline$\Delta$ (knufus) & 0.929991 & 9.727383 & 0.095605 & 0.0924 \\
\hline$\Delta$ (knufus(-1)) & -15.25851 & 14.65708 & -1.041034 & 0.0311 \\
\hline$\Delta$ (knufus(-2)) & 6.448887 & 6.284025 & 1.026235 & 0.3184 \\
\hline$\Delta$ (knufus(-3)) & -4.160026 & 2.367303 & -1.757285 & 0.0959 \\
\hline C & 11.61953 & 3.122412 & 3.721333 & 0.0016 \\
\hline ECM(-1) & -0.662861 & 0.114554 & -5.786430 & 0.0000 \\
\hline
\end{tabular}

Tablo 6'da gösterilen ECM(-1) katsayısının - 1 ile 0 arasında ve istatistiksel olarak anlamlı olması beklenmektedir. İstatistiksel olarak anlamlı bir ECM(-1) katsayısı, modelde kısa dönemde sapma olduğunu, mutlak değerce birden küçük oluşu ise sapmanın belli bir yüzdesinin ilerleyen dönemlerde düzeltildiğini ifade etmektedir. Katsayılar incelendiğinde; uzun dönemde değişkenler arasında meydana gelen bir sapma bir sonraki dönemde ( 1 yılda) \%66,2 oranında birbirine yaklaşıyor, dengeye yakınsıyor demektir. Ayrıca; kısa dönemde kentsel istihdamda meydana gelen \%1'lik değişim kentsel işsizliği \%0,9 oranında azalışa, kentsel nüfusta meydana gelen \%1'lik değişim kentsel işsizliği \%0,9 azalışa neden olurken, sonraki dönemlerde kentsel nüfusta meydana gelen değişimler kentsel işsizlikte bazı dönemler artışa bazı dönemler azalışa neden olmaktadır. 


\section{Şekil 4: CUSUM ve CUSUM-SQ Grafikleri}

\section{5}

10

5

0

$-5$

$-10$

$-15$

$\begin{array}{lllllllll}2002 & 2004 & 2006 & 2008 & 2010 & 2012 & 2014 & 2016 & 2018\end{array}$

_ CUSUM ----5 5 Significance

1.6

1.2

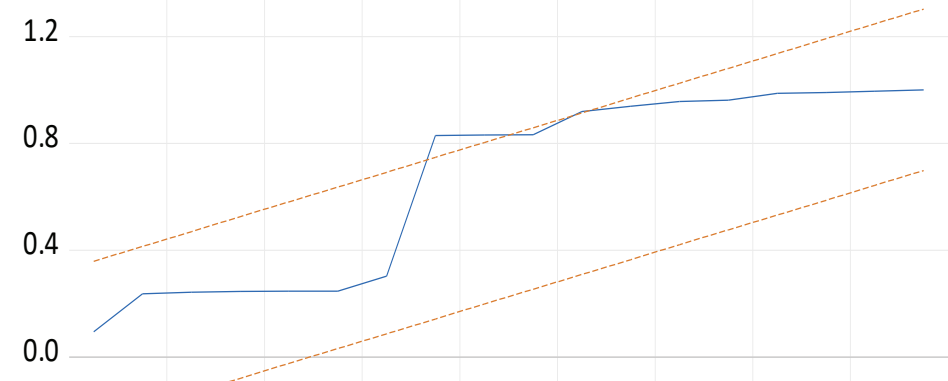

$-0.4$

$\begin{array}{lllllllll}2002 & 2004 & 2006 & 2008 & 2010 & 2012 & 2014 & 2016 & 2018\end{array}$

__ CUSUM of Squares -----. 5\% Significance

Şekil 4'de CUSUM ve CUSUM-SQ testleri sunulmuştur. CUSUM testi hata terimlerinin, CUSUM-SQ testi kümülatif hata terimlerinin karelerinin \%95 güven aralığında istenen sınırlar dahilinde olup olmadığını temsil etmektedir. Hata terimleri istenen güven aralığı içindeyse modelin katsayılarının istikrarlı olduğu sonucuna ulaşılmaktadır. Şekil 4'de görülen CUSUM-SQ grafiğinde 2009'un 3. çeyreğinden 2010'un 3. çeyreğine kadar olan dönem güven aralığı dışındadır. 2008 krizinin etkisinin katsayılarda istikrar kaybına yol açı̆ı̆ı görülmektedir. 
Tablo 7: Varsayımdan Sapma Testleri

\begin{tabular}{|c|c|c|c|}
\hline \multirow{2}{*}{ Model } & \multicolumn{3}{|c|}{ Breusch-Godfrey LM Testi } \\
\hline & Chi-square & Olasılık >chi-sq & Otokorelasyon \\
\hline \multirow{12}{*}{ ARDL $(1,2,4)$} & 0.1758 & 0.4295 & Bulunmamaktadır. \\
\hline & \multicolumn{3}{|c|}{ Jargue-Bera Normallik Testi } \\
\hline & Chi-square & Olasılık >chi-sq & Kalıntı \\
\hline & 2.15006 & 0.3412 & Normal Dağılıyor. \\
\hline & \multicolumn{3}{|c|}{ Breusch-Pagan Heteroskedasite Testi } \\
\hline & Chi-square & Olasılık >chi-sq & Heteroskedasite \\
\hline & 7.66591 & 0.6579 & Bulunmamaktadır \\
\hline & \multicolumn{3}{|c|}{ Ramsey Reset Testi } \\
\hline & Değer & Olasılık >chi-sq & Model Kurma Hatası \\
\hline & 1.3940 & 0.2540 & Bulunmamaktadır \\
\hline & Adj. $\mathrm{R}^{2}: 0.723078$ & DW: 2.2844 & \\
\hline & F-İst: 11.07148 & Olasılık: 0.000011 & \\
\hline
\end{tabular}

Modele ait varsayımdan sapma testleri Tablo 7'de verilmiştir. Heteroskedasite hata terimlerinin varyanslarının sabit olmamasıdır. Heteroskedasite, diğer bir ifade ile, değişen varyansın boş ve alternatif hipotezi; $\mathrm{HO}$ : değişen varyans yoktur, $\mathrm{H1}$ : varyanslar değişkendir. Otokorelasyon hata terimlerinin önceki dönemlerle ardışı bağımlı olmasıdır. Otokorelasyonun boş ve alternatif hipotezi HO: Hata terimleri ardışık bağımlı değildir ve H1: Hata terimleri ardışık bağımlıdır şeklindedir. Sağlıkı bir regresyonda olması gereken temel özelliklerden bir diğeri ise hata terimlerinin normal dağılmasıdır. Aralık tahminleri ve regresyon analizinde hata terimlerinin normal dağılıyor olması önemli bir kıstastır. Teste ait hipotezler HO: Kalıntılar normal dağılmaktadır ve H1: Kalıntılar normal dağılmamaktadır şeklindedir. Tablo 7'de sunulan düzeltilmiş $\mathrm{R}^{2 \prime}$ ye göre kentsel istihdam ve kırsal nüfusun toplam nüfustaki payı kentsel işsizlikte değişimi $\% 72$ oranında açıklayabilmektedir.

\section{Sonuç}

Uluslararası veya ulusal düzeyde gerçekleştirilen insan akışlarının terk edilen bölgenin yaşam koşullarının, tercih edilen bölgeye göre daha olumsuz olduğu gözlemlenmektedir. Aynı zamanda az gelişmiş bölgelerden gelişmiş bölgelere 
yapılan göçler sonrasında çarpık kentleşme, suç oranlarında artış, bireylerarası iletişim sorunları, sosyal uyumsuzluk gibi sorunlar ortaya çıkmaktadır.

Türkiye'de yıllar içinde gerçekleşen iç göç hareketleri sonucunda bölgelerarası gelişmişlik ve nüfus yoğunluklarında farklılıklar meydana gelmiştir. Bu açıdan bakıldığında, iç göç hareketleri bu farklılıkları ortaya çıkarmışken, bölgelerarası farklılıklar da iç göçü tetiklemiştir. Şehirlerin sunduğu hizmet standartları daha cazip geldiği için bölgelerarasında sağlık, çevre, istihdam, sosyal ve iktisadi faktörlerde değişmeler ortaya çıkmıştır. Ülkenin doğu bölgelerinden özellikle Marmara Bölgesi'ne yoğun geçişler yaşanmıştır. Bu durumun başlıca sebepleri arasında tarımda makineleşmenin artması ile köylerde artan işsizlik, şehirlerdeki eğitim olanakları ve güvenlik sorunu yer almaktadır.

Bu çalışmada tahmin edilen model sonucunda, Türkiye'de 1988-2019 yıllarında kentsel istihdam oranı, kırsal nüfus oranı ve kentsel işsizlik oranı arasında anlamlı bir ilişki olduğu sonucuna ulaşılmıştır. Analiz sonucu, Türkiye'de kentlerdeki istihdam olanaklarının artışının kentsel işsizlik oranını azaltması yönündeki olumlu etkinin iç göçler sonucu azaldığını ortaya koymaktadır. Bu sonuç ise Todaro Paradoksunun 1988-2019 yılları arasında Türkiye'de geçerli olduğunu göstermektedir. Diğer bir ifade ile, kentlerde istihdam imkanlarının artmaya devam etmesi kentlere olan göçü tetiklemekte, kentlerde işsizliği kalııı hale getirmektedir. Elde edilen bulgular, kentlere yapılan göçler ve kentlerdeki işsizlik ilişkisini inceleyen çalışmalar ile paralellik göstermektedir.

Büyükşehirlerdeki nüfus yoğunluğu, çarpık kentleşme, altyapının yetersiz kalışı, trafik sorunu gibi birçok hususta göçlerin payı olduğunu söylemek yanlış olmayacaktır. Kentlerde yaşanan sorunları çözmek üzere, merkezinde yalnızca kentlerin olduğu politika paketleri geliştirmek yeterli olmayacaktır. Kentlerde yaşanan sorunları çözmeye yönelik politikaların, kırsaldaki işsizliğin azaltılması ve yaşam standartlarının geliştirilmesine yönelik bölgesel politikalar ile desteklenmesi gerekmektedir. Zira bireyler bulundukları bölgede işsizlik sorunu ile karşı karşıya kalmayacak, eğitim, sağlık, güvenlik faaliyetlerinin yeterli düzeyde olduğu kanaati taşırsa göç etme konusunda daha temkinli davranışlar sergileme eğilimine 
gireceklerdir. Göçe sebebiyet veren önemli tetikleyicilerden biri olan kırsal kesimdeki gelirin kente oranla düşük kalması, göçün önüne geçebilmek ve tersine göçü teşvik edebilmek adına kırsal kalkınma politikaları açısından çözülmesi gereken en önemli sorunlardan biri olacaktır.

\footnotetext{
Etik Komite Onayı: Çalışma etik kurul onayı gerektirmemektedir.

Hakem Değerlendirmesi: Dış bağımsız.

Yazar Katkıları: Çalışma Konsepti/Tasarım- E.K., İ.Y.D.; Veri Toplama- I.Y.D.; Veri Analizi/Yorumlama- İ.Y.D.; Yazı Taslă̆ıE.K., İ.Y.D.; İçeriğin Eleştirel İncelemesi- E.K., İ.Y.D.; Son Onay ve Sorumluluk- E.K., İ.Y.D.

Çıkar Çatışması: Yazarlar çıkar çatışması bildirmemiştir.

Finansal Destek: Yazarlar bu çalışma için finansal destek almadığını beyan etmiştir.

Ethics Committee Approval: The study does not require ethics committee approval.

Peer-review: Externally peer-reviewed.

Author Contributions: Conception/Design of Study- E.K., I.Y.D.; Data Acquisition- I.Y.D.; Data Analysis/Interpretation- İ.Y.D.; Drafting Manuscript- E.K., I.Y.D.; Critical Revision of Manuscript- E.K., I.Y.D.; Final Approval and Accountability- E.K., I.Y.D. Conflict of Interest: The authors have no conflict of interest to declare.

Grant Support: The authors declared that this study has received no financial support.
}

\section{Kaynaklar/References}

Akkayan, T. (1979). Göç ve Değişme. İstanbul: Edebiyat Fakültesi Basımevi.

Barut, M. (2011). Zorla yerinden edilenler için ekonomik, sosyal ve kültürel haklar araştırma raporu. Can Matbaacilik, Mersin.

Birinci, S. (2017). Türkiye'de göç etkinliği, nüfus devinimi ve nüfus değişimi (2015-2015). Türk Coğrafya Dergisi, Cilt.69, ss.81-88

Cerit, S. (1986). Türkiye'de iller arası göçler: 1950-1980. Nüfus Bilim Dergisi, Cilt.8, ss.81-103.

Çelik, F. (2007). Türkiye'de iç göçler:1980-2000. Erciyes Üniversitesi Sosyal Bilimler Enstitüsü Dergisi, Cilt.22 Sayı.1, ss.87-109.

Engle, Robert F. and C.W.J. Granger, (1987). Cointegration and error correction: Representation, Estimation and Testing, Econometrica, Nu.55, pp.251-276.

Eraydın, A. (1981). Türkiye'de 1950-1980 döneminde iller arası göçlerin değerlendirilmesi. Devlet Planlama Teşkilatı.

Ercilasun, M., Gencer, Eve Esin, Ö. (2011). Türkiye'deki iç göçleri belirleyen faktörlerin modellenmesi. Büyüme ve Gelişme, ss.319-324.

Friedman, J. (1966). Regional development policy. Cambridgde, M.I.T. Press.

Gedik, A. (1994). Türkiye'de iç göçler, 1965-85: bazı varsayımların sorgulanması. ODTÜ Mimarlık Fakültesi Yayını, ss. 213-232.

Griworld, D.(2009). Higher immigration, lower crime, commentary. Nu.128, pp.42-46.

Gür, T.H. ve E. Ural (2004), "Türkiye' de kentlere göçün nedenleri". Hacettepe Üniversitesi IIIBF Dergisi, Cilt.22, Sayı.1, ss.23-38. 
Harris, J. And Todaro, M. (1970). Unemployment and development: a two-sector analysis. The American Economic Review, Vol. 60, Nu. 1, pp. 126-142.

Hutchinson, M.(2009). Securing the borders: debating immigration policy in U.S. history. Oah Magazine of History, Nu.23, pp.46-9.

İçduygu, A. ve Sirkeci, İ. (1999). Cumhuriyet dönemi Türkiye'sinde göç hareketleri". Oya Baydar (Ed.), 75 Yılda Köylerden Şehirlere, Tarih Vakfı Yayınları.

Johansen, S. (1988). Statistical analysis of cointegration vectors. Journal of Economics Dynamic and Control, 12(2-3), pp.231-254.

Johansen, S. and Katarina Juselius (1990). Maximum likelihood estimation and inference on cointegration with applications to the demand for money. Oxford Bulletin of Economics' and Statistics, Nu.52, pp.169-210.

Kıratoğlu, E. (2019). Küreselleşen ekonomik düzende göç: trc2 bölgesi örneği, küreselleşmenin ekonomik boyutları. Gazi Kitabevi, ss.105-126.

Kocaman, T. ve Bayazıt, S. (1993). Türkiye'de iç göçler ve göç edenlerin sosyo-ekonomik nitelikleri. Devlet Planlama Teşkilatı.

Kurt, H. (2003). "Türkiye'de kent-köy çelişkisi", Ankara:Siyasal Kitabevi.

Kuznets, S. (1963). Consumption, industrialization and urbanization, in B.F. Hoselitz, W.E. Moore(ed.s). Industrialization and Society, Unesco-Mouton.

Lee, E. S. (1966). A theory of migration. Demography, Vol.3, Nu.1, pp.47-57.

Lewis, A. (1954). Economic development with unlimited supplies of labour. The Manchester School, pp.139-191.

Mutlu, S. (1990). Bölgesel iç ticaret hadleri, kırsal refah ve iç göçler. Ekonomi ve İdari Bilimler Dergisi, Cilt. 4, Sayı. 1, ss. 69-87.

Nakagome, M. (1989), "Urban unemployment and the spatial structure of labor markets: an examination of the todaro paradox in a spatial context". Journal of Regional Science, Vol.29, pp.161-170.

Narayan, S. ve Narayan, P.P. (2004). Determinats of demand of fiji's exports: an empirical investigation. The Developing Economics. Vol.17, Nu.1, pp.95-11.

Okun, B., \& Richardson, R. W. (1961). Regional income inequality and internal population migration. Economic Development and Cultural Change, Vol.9, Nu.2, pp.128-143.

Özdemir, H. (2012). Türkiye'de iç göçler üzerine genel bir değerlendirme". Akademik Bakış Dergisi, Cilt.11.

Pesaran, M. H., Y. Shin ve R. J. Smith (2001). Bounds testing approaches to the analysis of level relationships. Journal of Applied Econometrics, Nu.16, pp. 289-326.

Ravenstein, E. G (1885). The laws of migration, Journal of the Statistical Society of London, Vol.48, Nu.2, pp.167-235.

Resmi Gazete, Sayı. 28489, 6360 Sayılı on dört ilde büyükşehir belediyesi ve yirmi yedi ilçe kurulması ile bazı kanun ve kanun hükmünde kararnamelerde değişiklik yapılmasına dair kanun. 
Sjaastad, L. A. (1962). The costs and returns of human migration. Journal of Political Economy, Vol.70, pp.80-93.

Stouffer, A. S. (1940). Intervening opportunities: a theory relating mobility and distance. American Sociological Review, Vol.5, Nu.6.

Şahin, A. (2018). Harris-Todaro göç modeli: Türkiye uygulaması. (Yayınlanmamış Yüksek Lisans Tezi), Mersin Üniversitesi Sosyal Bilimler Enstitüsü, Mersin.

Şen, M. (2014). Türkiye'de iç göçlerin neden ve sonuç kapsamında incelenmesi. Çalışma ve Toplum Dergisi, Sayı. 1, ss.248 - 276.

Takagi, Y. (1984). The migration function and the todaro paradox. Reg. Sci. Urb. Eco., Vol. 14, pp.219230.

Tekeli, İ. (1975). Göç teorileri ve politikaları arasındaki ilişkiler. ODTÜ Mimarlık Fakültesi Dergisi, Cilt 1, Sayı 1, ss.153-176.

Tekeli, İ. (1998). Türkiye'de iç göç sorunsalı yeniden tanımlama aşamasına geldi, Türkiye'de içgöç ve iç̧öçün işçi hareketlerine etkisi. A. İçduygu vd. (Der.), Türkiye Ekonomik ve Toplumsal Tarih Vakfı, ss.7-21,

Todaro, M. P. (1969). A model of labor migration and urban unemployment in less developed countries. The American Economic Review, Vol.59, Nu.1, pp.138-148.

Toksöz, G. (2006). Uluslararası emek göçü. İstanbul, Bağlam Yayınları.

Tolley, G.S., (1963). Population adjustment and economic activity; three studies. Papers and Proceedings of the Regional Science Association, Vol.11.

Tümertekin, E. (1971). Gradual internal migration in Turkey: a test of ravenstein's hypothesis. The Review of The Geographic Institute of The University of İstanbul, Nu. 13.

Tümertekin, E. (1977). Türkiye'de iç göçler üzerine. İstanbul Üniversitesi Edebiyat Fakültesi Coğrafya Enstitüsü.

Tümtaş, M. S ve Ergun C. (2014). Göç ve yoksulluk kıskacında yıkılan bir kent: Van. Akademik Yaklaşımlar Dergisi, Cilt.5, Sayı.2, ss.1-23.

Uluslararası Göç Örgütü, Göç Terimleri sözlüğü. İkinci Baskı, No:31.

Wolpert, J. (1966). Migration as an adjustment to environment stress. Journal of Social Issue, Vol.22, Nu.4, pp.92-102.

Yamak, R. ve N. Yamak (1999). Türkiye'de gelir dağılımı ve iç göç. Dokuz Eylül Üniversitesi Sosyal Bilimler Enstitüsü Dergisi, Cilt.1, Sayı.1, ss. 16-28.

Yener, S. (1977). 1965-1970 Döneminde iller arası göçler ve göç edenlerin nitelikleri. Devlet Planlama Teşkilatı. 